\title{
A fast and direct spectrophotometric method for the sequential deter- mination of nitrate and nitrite at low concentrations in small volumes
}

\author{
Emilio García-Robledo ${ }^{1,2^{*}}$, Alfonso Corzo ${ }^{1}$, Sokratis Papaspyrou ${ }^{1}$ \\ 1 Departamento de Biología. Facultad de Ciencias del Mar y Ambientales, Universidad \\ de Cádiz, Pol. Río San Pedro s/n. 11510- Puerto Real, Spain \\ 2 Section of Microbiology. Department of Biological Sciences. Aarhus University. DK-8000 Aarhus C, Denmark
}

\author{
* Corresponding author \\ Section of Microbiology. \\ Department of Biological Sciences. \\ Aarhus University. \\ DK-8000 Aarhus C, \\ Denmark \\ e-mail: emilio.garcia@biology.au.dk
}

\begin{abstract}
The use of vanadium (III) has been proposed recently as a suitable alternative to cadmium for the reduction of $\mathrm{NO}_{3}{ }^{-}$to $\mathrm{NO}_{2}{ }^{-}$during spectrophotometric analysis. However, the methods proposed suffer from decreased sensitivity and additional steps for the measurements of nitrite and nitrate. We have developed an improved fast and sequential protocol that permits the determination of low concentrations of nitrite and nitrate in marine and freshwater samples using small volumes. $\mathrm{NO}_{2}$ - concentration is firstly determined using the common Griess reaction. The subsequent addition of a $2 \%$ $\mathrm{VCl}_{3}$ solution in $6 \mathrm{~N} \mathrm{HCl}$ in the same sample and the reaction at $60^{\circ} \mathrm{C}$ for 25 minutes results in an efficient reduction of the $\mathrm{NO}_{3}{ }^{-}$to $\mathrm{NO}_{2}{ }^{-}(>95 \%)$, which is also detected by the already added Griess reagents. The method has a detection limit $<0.05 \mu \mathrm{M}$, a high precision (ranging from 0.2 to $11 \%$ ) and accuracy $\left(0.07 \mu \mathrm{M}\right.$ ) for the determination of $\mathrm{NO}_{3}{ }^{-}+\mathrm{NO}_{2}{ }^{-}$ concentrations lower than $30 \mu \mathrm{M}$. Comparison of the proposed method with the established Cd column method using samples from a variety of environments (fresh water reservoir, sediment freeze lysable pore water, estuarine water samples and samples from an acid mine drainage impacted reservoir) showed good agreement between the two methods, with a difference between methods of $0.073 \pm 0.099 \mu \mathrm{M}$. The analysis can be performed in large batches ( $\sim 60$ samples) using small sample volumes $(\leq 1 \mathrm{~mL})$ for the determination of both $\mathrm{NO}_{3}{ }^{-}$and $\mathrm{NO}_{2}{ }^{-}$in less than one hour.
\end{abstract}

Keywords (3-6 alphabetical): Nitrite; Nitrate; Griess reaction; Vanadium (III) chloride; spectrophotometric method 


\section{Introduction}

Nitrate is a key compound in the $\mathrm{N}$ cycle of natural ecosystems and artificial environments, being substrate or product of several microbial, plant, and animal metabolic processes. In aquatic environments, nitrate is produced by nitrification in a two-step reaction: ammonium oxidation to nitrite and nitrite oxidation to nitrate. Nitrate can then be assimilated by photosynthetic organisms, thus being an important nutrient for primary production. Nitrate is also consumed in a variety of bacterial processes such as the anaerobic denitrification or dissimilatory nitrate reduction to ammonium (DNRA). Denitrification reduces nitrate to nitrous oxide, a potent greenhouse gas (Lashof and Ahuja, 1990), or molecular nitrogen gas, reducing the nitrogen load of the system, whereas DNRA reduces nitrate to biologically available ammonium that remains in the system (Megonigal et al., 2003). Therefore, the measurement of nitrate and nitrite concentrations in aquatic systems is an important aspect of most studies related to the $\mathrm{N}$ cycle in order to determine its production and consumption rates.

Numerous methods for the determination of nitrate are available in the literature. Highly sensitive methods are based on the reduction of nitrate to nitric oxide, which is quantified by chemiluminiscence (Aoki et al., 1997; Braman and Hendrix, 1989), or to nitrous oxide, later quantified by gas chromatography (Christensen and Tiedje, 1988). However, both these techniques require expensive and specialized equipment. Other methods involve the use of strong acids often at elevated temperatures (Mir, 2008; Zhang and Fischer, 2006), which complicates handling and analyses of the samples. In contrast, the simplest and most regularly applied method involves the reduction of nitrate to nitrite and its subsequent measurement by colorimetry using the Griess reaction (Grasshoff et al., 1983; Marzinzig et al., 1997). This method has low detection limit, high accuracy and high specificity without using expensive instruments or complex procedures.

The critical step for the accurate determination of nitrate is its efficient reduction to nitrite. Nitrate reduction to nitrite can be accomplished by specific nitrate reductases (Guevara et al., 1998; Marzinzig et al., 1997) or by the use of different reducing metals, with cadmium being the most commonly used one (Grasshoff et al., 1983; Wood et al., 1967). Although various adaptation of the cadmium reduction method have been proposed in order to increase sample throughput and decrease sample volume required (Harris and Mortimer, 2002; Jones, 1984), the method suffers from various shortcomings; it is time consuming, efficiency of the column varies, a continuous activation of the Cd-column is required, and cadmium is highly toxic (European Chemical Agency: www.echa.europa.eu and Occupational Safety and
Health Administration, United States Department of Labor: www.osha.gov) making handling of samples and waste hazardous.

Miranda et al. (2001) described a spectrophotometric method using a vanadium solution $\left(\mathrm{VCl}_{3}\right)$ for the reduction of nitrate. V(III), which is less toxic than cadmium (European Chemical Agency and Occupational Safety and Health Administration, United States Department of Labor), has been commonly used for the reduction of both nitrate and nitrite at high temperatures $\left(80-90^{\circ} \mathrm{C}\right)$ to nitric oxide, then measured by chemiluminiscence (Braman and Hendrix, 1989). Miranda et al. (2001) showed that at room temperatures nitrate is reduced to nitrite, which can react with Griess reagents and be measured in a spectrophotometer. However, the proposed protocol resulted in a low molar absorptivity for nitrate, indicating low reaction efficiency in the reduction of $\mathrm{NO}_{3}^{-}$to $\mathrm{NO}_{2}^{-}$. As a result, nitrite highly interferes with the determination of nitrate. Beda and Nedospasov (2005) included an initial step in the method for the elimination of nitrite by the reaction with sulfamic acid, reducing thus the high $\mathrm{NO}_{2}^{-}$interference in the $\mathrm{NO}_{3}{ }^{-}$determination. However, as the subsequent steps involving the reduction of $\mathrm{NO}_{3}{ }^{-}$to $\mathrm{NO}_{2}^{-}$were not modified, the overall efficiency of the reaction was not improved. As a result the precision of the method was lower than that using the classic Cdcolumns for nitrate reduction.

We describe here an optimised protocol for the sequential measurement of nitrite and nitrate in small volumes $(<1 \mathrm{~mL})$ of the same sample by adjusting factors such as vanadium chloride and $\mathrm{HCl}$ concentrations, temperature and time of reaction that improved the efficiency of the nitrate reduction to nitrite and the signal measured. As a result, efficiencies higher than 95\% were obtained, resulting in a simple, fast and accurate method for the determination of nitrate and nitrite. The proposed methodology was also compared with the most widely used method for $\mathrm{NO}_{3}^{-}$analysis, the $\mathrm{Cd}$ column method) by analysing in parallel samples from different environments (fresh water reservoir, sediment freeze lysable pore water, estuarine water samples and samples from an acid mine drainage impacted reservoir).

\section{Materials and methods}

\section{Instrumentation}

Spectrophotometric measurements were performed on Unicam UV/Vis UV2-200 spectrophotometer (Unicam, U.K.) using 1-cm path length quartz cuvettes. The spectrophotometer was equipped with a thermostatized cuvette holder regulated by an external water bath. The UV-probe software (Unicam, U.K.) was used to control measurements and record absorbance spectra. Spectrophotometric measurements in 96-well mi- 
croplates were performed on a microplate reader Powerwave 340 (Bio-Tek Instruments Inc., USA), using the control program KC JuniorTM Data Analysis software. Incubations of samples were performed in a temperature controlled water bath Unitronic OR (JP Selecta, Spain).

\section{Reagents and standards}

Reagents were of analytical purity grade. All solutions and dilutions were prepared with pure water (Milli -Q). Griess reagents for the analysis of $\mathrm{NO}_{2}^{-}$were prepared as described in Grasshoff. et al. (1983). Sulphanilamide reagent was prepared by dissolving $5.0 \mathrm{~g}$ of sulphanilamide in $50 \mathrm{~mL}$ of concentrated $(12 \mathrm{~N})$ hydrochloric acid $(\mathrm{HCl})$ diluted in about $300 \mathrm{~mL}$ of pure water and after cooling made up to $500 \mathrm{~mL}$ with pure water. N-(1-naphthyl)-ethylenediamine dihydrochloride (NED) reagent was prepared by dissolving $0.5 \mathrm{~g}$ NED in $500 \mathrm{~mL}$ of pure water (MiliQ). Both reagents were mixed in equal proportions just prior to performing the analysis (hereafter referred as Griess-reagent). Reagents were stored in glass dark bottles and maintained at $4^{\circ} \mathrm{C}$. The reagents are stable for at least one month. NED reagent can be used until a brown discoloration occurs.

Vanadium (III) chloride $\left(\mathrm{VCl}_{3}\right)$ reagent $2 \% \mathrm{w} / \mathrm{v}$ was prepared in a $6 \mathrm{~N} \mathrm{HCl}$ solution $\left(\mathrm{VCl}_{3}\right.$-reagent). The time needed for the complete dissolution varies depending on the concentration used but was generally about 1 hour. The complete dissolution was evidenced by the shift from a turbid to a transparent solution. The solution was finally filtered through a $0.7 \mu \mathrm{m}$ nominal pore size glass fibre filter in order to eliminate any impurities of the reagent. $\mathrm{VCl}_{3}$-reagent was prepared weekly and stored in a dark glass bottle at $4^{\circ} \mathrm{C}$. The $\mathrm{VCl}_{3}$ reagent is stable for several months.

Artificial seawater was prepared following the complete salt composition described by Grasshoff et al. (1983).

Stock nitrate standard solutions $(10 \mathrm{mM})$ were prepared by dissolving $1.011 \mathrm{~g}$ oven dried $\left(100^{\circ} \mathrm{C}, 1 \mathrm{~h}\right)$ $\mathrm{KNO}_{3}$ in $1 \mathrm{~L}$ pure water. Stock nitrite solution $(10 \mathrm{mM})$ was prepared by dissolving $0.690 \mathrm{~g} \mathrm{NaNO}_{2}$ to $1 \mathrm{~L}$ of pure water. Working solutions were prepared from stock solutions as required by dilution with pure water for all the initial optimization experiments. Standard solutions were prepared in artificial seawater of the appropriate salinity for the salinity effect experiment.

\section{Proposed procedure for the sequential determina- tion of $\mathrm{NO}_{2}^{-}$and $\mathrm{NO}_{3}^{-}$}

A 2-step protocol was tested and validated, in order to allow the sequential determination of both $\mathrm{NO}_{2}^{-}$and $\mathrm{NO}_{3}{ }^{-}$in the same sample as follows:

\section{Step 1: Nitrite determination}

One $\mathrm{mL}$ of sample was transferred into $1.5 \mathrm{~mL}$ eppendorf vials followed by the addition of Griessreagent $(50 \mu \mathrm{L})$ and gently mixed. Vials were incubated at ambient temperature $\left(\sim 25^{\circ} \mathrm{C}\right)$ for $20 \mathrm{~min}$. Then, 350 $\mu \mathrm{L}$ of this solution (sample + reagents) were transferred into 96-well flat bottom polysterene microplates and absorbance was measured at $540 \mathrm{~nm}$. $\mathrm{NO}_{2}{ }^{-}$concentrations was determined by parallel analysis of a set of $\mathrm{NO}_{2}^{-}$standards.

\section{Step 2: Nitrite plus Nitrate determination}

A volume $(70 \mu \mathrm{L})$ of $\mathrm{VCl}_{3}$-reagent was added to the remaining sample volume $(700 \mu \mathrm{L})$ in the eppendorf vials. The vials were closed to prevent evaporation, gently mixed and incubated in a temperature-controlled bath at $60^{\circ} \mathrm{C}$ for $25 \mathrm{~min}$. Then, the vials were cooled down to room temperature in a water bath and $350 \mu \mathrm{L}$ of each sample was transferred into 96-well microplates and the absorbance was measured at $540 \mathrm{~nm}$. Parallel analysis of a set of $\mathrm{NO}_{2}^{-}$and $\mathrm{NO}_{3}{ }^{-}$standards were performed simultaneously for the determination of $\mathrm{NO}_{3}$ concentration as described below.

\section{Calibration curves}

- Nitrite determination (Step 1)

During step 1 a set of $\mathrm{NO}_{2}^{-}$standards is used to determine the concentrations of $\mathrm{NO}_{2}^{-}$in the standard/ sample using the equation:

$$
\mathrm{ABS}_{\mathrm{NO} 2}^{1}=\mathrm{S}_{\mathrm{NO} 2}^{1} \times\left[\mathrm{NO}_{2}^{-}\right]+\mathrm{ABS}_{\text {reagents }}^{1}(1)
$$

Where $\mathrm{ABS}^{1}{ }_{\mathrm{NO} 2}$ is the absorbance of the $\mathrm{NO}_{2}{ }^{-}$standards; $\mathrm{S}_{\mathrm{NO} 2}^{1}$ is the slope of the calibration curve (ABS $\mu \mathrm{M}^{-1}$ ) for $\left.\mathrm{NO}_{2}^{-} ; \mathrm{NO}_{2}^{-}\right]$is the $\mathrm{NO}_{2}^{-}$concentration, and $\mathrm{ABS}_{\text {reagents }}^{1}$ is the absorbance of the reagents, i.e. the intercept of the calibration curve

\section{- Nitrate determination (Step 2)}

In the samples, where both $\mathrm{NO}_{2}^{-}$and $\mathrm{NO}_{3}{ }^{-}$are present, it is necessary to discriminate between the contributions from the two compounds. After the reaction with $\mathrm{VCl}_{3}$-reagent, the measured absorbance $\left(\mathrm{ABS}^{\mathrm{V}}{ }_{\mathrm{NOX}}\right)$ is a combination of the individual contribution of each compound $\left(\mathrm{NO}_{2}{ }^{-}\right.$and $\left.\mathrm{NO}_{3}{ }^{-}\right)$plus the absorbance of the reagents, i.e.:

$$
\mathrm{ABS}_{\mathrm{NOX}}^{\mathrm{V}}=\mathrm{ABS}_{\mathrm{NO} 2}^{\mathrm{V}}+\mathrm{ABS}_{\mathrm{NO} 3}^{\mathrm{V}}+\mathrm{ABS}_{\text {reagents }}^{\mathrm{V}}
$$

The use of $\mathrm{NO}_{2}{ }^{-}$standards and $\mathrm{NO}_{3}{ }^{-}$standards allow performing a calibration of the complete reaction in the presence of $\mathrm{VCl}_{3}$-reagent, being:

$$
\mathrm{ABS}_{\mathrm{NO} 2}^{\mathrm{V}}=\mathrm{S}_{\mathrm{NO} 2}^{\mathrm{V}} \times\left[\mathrm{NO}_{2}^{-}\right]+\mathrm{ABS}_{\text {reagents }}^{\mathrm{V}}
$$




$$
\mathrm{ABS}^{\mathrm{V}}{ }_{\mathrm{NO} 3}=\mathrm{S}_{\mathrm{NO} 3}^{\mathrm{V}} \mathrm{x}\left[\mathrm{NO}_{3}^{-}\right]+\mathrm{ABS}_{\text {reagents }}^{\mathrm{V}}
$$

where, $\mathrm{ABS}^{\mathrm{V}}{ }_{\mathrm{NO} 2}$ and $\mathrm{ABS}^{\mathrm{V}}{ }_{\mathrm{NO} 3}$ are the absorbance of the $\mathrm{NO}_{2}^{-}$and $\mathrm{NO}_{3}{ }^{-}$standard, respectively; $\mathrm{S}^{\mathrm{V}}{ }_{\mathrm{NO} 2}$ and $\mathrm{S}^{\mathrm{V}}{ }_{\mathrm{NO} 3}$ are the slope of the calibration curves (ABS $\mu \mathrm{M}^{-}$ $\left.{ }^{1}\right)$ for $\mathrm{NO}_{2}^{-}$and $\mathrm{NO}_{3}^{-}$, respectively; $\left[\mathrm{NO}_{2}^{-}\right]$and $\left[\mathrm{NO}_{3}^{-}\right]$ are the $\mathrm{NO}_{2}^{-}$or $\mathrm{NO}_{3}^{-}$concentration of the standards, respectively and $\mathrm{ABS}^{\mathrm{V}}$ reagents is the absorbance of the reagents without $\mathrm{NO}_{2}{ }^{-}$or $\mathrm{NO}_{3}^{-}$, i.e. the intercept of the calibration curve.

The measured absorbance is a combination of the individual contribution of each compound plus the absorbance of the reagents, i.e. the combination of Equations 3 and 4:

$$
\begin{aligned}
\left.\mathrm{ABS}^{\mathrm{V}}{ }_{\mathrm{NOX}}=\mathrm{S}_{\mathrm{NO} 3}^{\mathrm{V}} \times \mathrm{NO}_{3}^{-}\right]+\mathrm{S}_{\mathrm{NO} 2}^{\mathrm{V}} & \left.\times \mathrm{NO}_{2}^{-}\right]+\mathrm{ABS}_{\text {reagents }}(5)
\end{aligned}
$$

The actual $\mathrm{NO}_{3}{ }^{-}$concentration of the sample is calculated as:

$$
\begin{aligned}
{\left[\mathrm{NO}_{3}{ }^{-}\right]=\left(\mathrm{ABS}^{\mathrm{V}}{ }_{\mathrm{NOX}}-\mathrm{ABS}^{\mathrm{V}}{ }_{\text {reagents }}-\mathrm{S}^{\mathrm{V}}{ }_{\mathrm{NO} 2}\right.} \\
\left.\times\left[\mathrm{NO}_{2}^{-}\right]\right) / \mathrm{S}^{\mathrm{V}}{ }_{\mathrm{NO} 3}(6)
\end{aligned}
$$

Where: $\left[\mathrm{NO}_{2}^{-}\right]$is the $\mathrm{NO}_{2}^{-}$concentration determined in the step 1 and $\left[\mathrm{NO}_{3}{ }^{-}\right]$is the $\mathrm{NO}_{3}{ }^{-}$concentration of the sample.

\section{Environmental samples}

A set of environmental samples were collected from different environments and analysed both with the traditional cadmium reduction method on a TRAACS 800 Technicon autoanalyser using standard protocols (Grasshoff et al 1983) and with the protocol described here. Estuarine water column surface samples were collected along a salinity gradient (salinity range 6-26) in the inner Gulf of Nicoya, Costa Rica in July 2011 (Seguro et al. in prep). Freshwater water column samples (0-16 $\mathrm{m}$ depth, salinity 0$)$ were collected from the Bornos water reservoir, SW Spain, in August 2010 (Romero-Martínez et al., 2013). Water column samples from an experiment using sediment cores from an acid mine drainage affected water reservoir, Sancho reservoir, SW Spain, were collected in December 2011 (Torres et al. 2013) to test for the effect of high metal concentrations. Water samples were filtered by $0.7 \mu \mathrm{m}$ glass fibre filters and stored frozen at $-20^{\circ} \mathrm{C}$ until analysis. Pore water nutrient samples extracted from frozen sediment cores (Freeze Lysable Inorganic Nutrients, FLIN) (0-3.5 cm depth, salinity 32-40) were collected from the Rio San Pedro tidal creek, SW Spain, in March 2013, using the procedure described in GarciaRobledo et al (2010). FLIN samples were stored frozen until analysis. Samples were aliquoted in triplicate and analysed with each method.

\section{Results \& Discussion}

\section{Effect of temperature, $\mathrm{VCl}_{\mathbf{3}}$ and $\mathrm{HCl}$ concentration}

Maximum absorbance and the corresponding minimum time needed to reach it as a function of varying $\mathrm{VCl}_{3}$ and $\mathrm{HCl}$ concentrations are represented in Figure 1. For $\mathrm{VCl}_{3}$, maximum absorbance was obtained when concentrations were equal or higher than $1 \%$, being maximum at $2 \%$ (Fig. 1A). In order to follow the effect of temperature on colour development, the cuvette holder of the spectrophotometer was maintained at a constant temperature while the absorbance was measured every 5 minutes.

Temperature had a significant effect, with absorbance being highest at $40^{\circ} \mathrm{C}$ and lowest at $80^{\circ} \mathrm{C}$ (Fig. 1A). However, the combined effects of temperature and $\mathrm{VCl}_{3}$ concentration strongly influenced the reaction time (Fig. 1C). Although the maximum colour development was measured at $40^{\circ} \mathrm{C}$, reaction times exceeded 2 hours, reducing its application for daily routine analysis. We also tested lower temperatures such as the ambient temperature $\left(25^{\circ} \mathrm{C}\right)$ which was used in the protocols by Beda and Nedospasov (2005) and Miranda et al. (2001); however, reaction times exceeded 5 hours (data not shown), and therefore temperatures lower than $40^{\circ} \mathrm{C}$ were not considered during subsequent tests. In contrast, temperatures of $50-70^{\circ} \mathrm{C}$ combined with $2 \% \mathrm{VCl}_{3}$ solution had high absorbances with reaction times $<1$ hour. The increase in temperature from 60 to $70^{\circ} \mathrm{C}$ did not affect the performance of the reaction substantially, so further comparisons were done between 50 and $60^{\circ} \mathrm{C}$.

We also tested for the effect of $\mathrm{HCl}$ concentration on the reaction. Maximum absorbance was measured when the concentration was higher than $4 \mathrm{~N}$ (maximum at 6-8 N) (Fig. 1B). Reaction time was also influenced by $\mathrm{HCl}$ concentration, decreasing exponentially to reaction time less than $30 \mathrm{~min}$ at concentrations $=6 \mathrm{~N} \mathrm{HCl}$ (Fig. 1D). Therefore, a concentration of $6 \mathrm{~N} \mathrm{HCl}$ was determined as the minimum concentration producing the maximum signal with the minimum reaction time. As a consequence, the conditions selected based on the current setup that resulted in the most efficient reaction overall was a solution of $2 \% \mathrm{VCl}_{3}$ in $6 \mathrm{~N} \mathrm{HCl}$ and a reaction temperature of $60^{\circ} \mathrm{C}$.

\section{Optimization of the temperature and reaction time for laboratory use}

The dependence of the maxima signal and reaction time on temperature was further tested using a temperature controlled water bath. This heating method is the most common procedure in laboratories and the heat transference efficiency is higher compared to that of the spectrophotometer's cuvette holder. At the highest tem- 

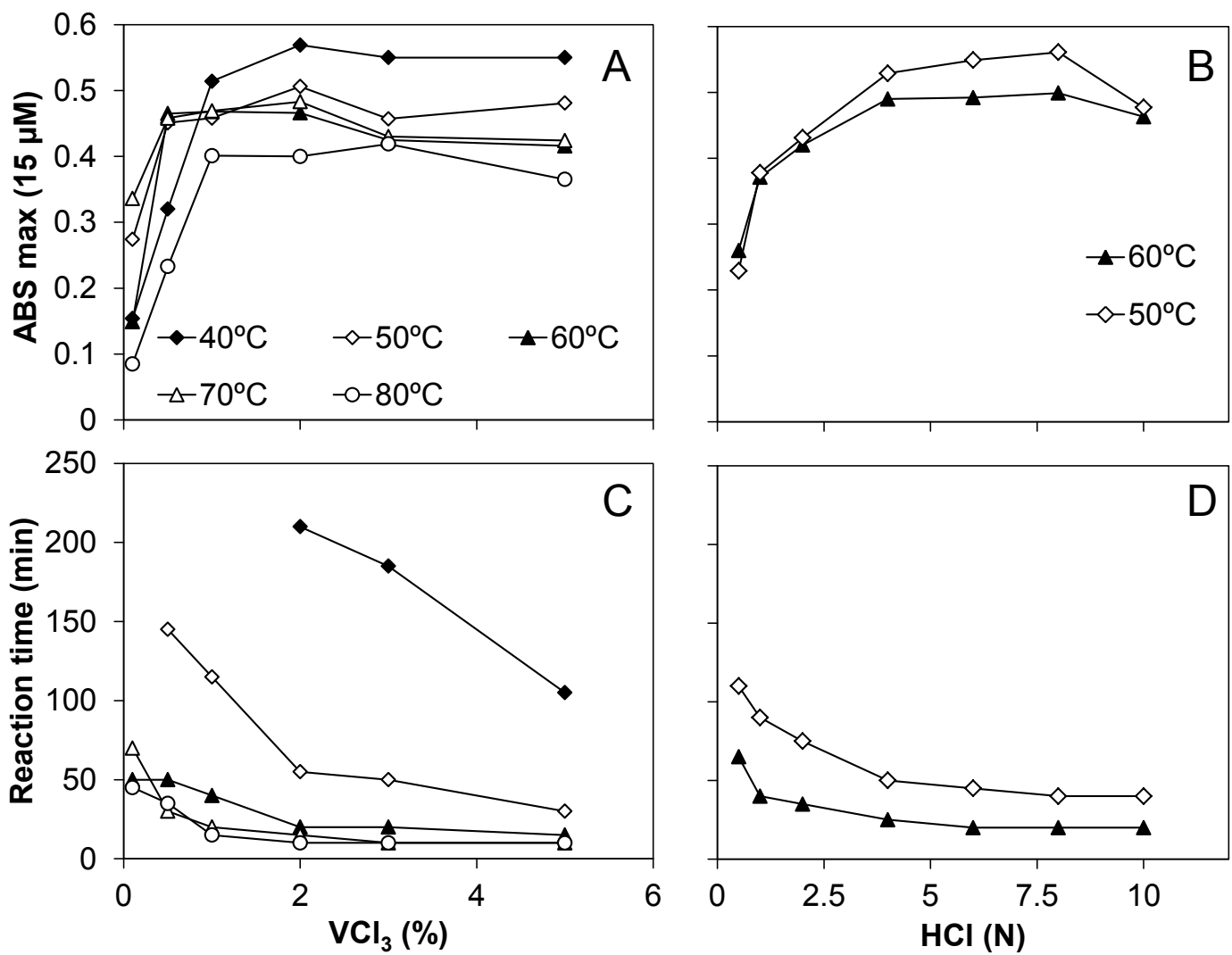

Figure 1. (A) Effect of varied temperature and $\mathrm{VCl}_{3}$ reagent concentration in $10 \mathrm{~N} \mathrm{HCl}$ on reduction and measurement of the maximum absorbance for a $15 \mu \mathrm{M} \mathrm{NO}_{3}{ }^{-}$solution $\left(2.5 \mathrm{~mL}\right.$ standard $+250 \mu \mathrm{L}$ Griess reagent $+250 \mathrm{VCl}_{3}$-reagent); (B) Effect of varied temperature and $\mathrm{HCl}$ concentration (using $2 \% \mathrm{VCl}_{3}$ ) on reduction and measurement of the maximum absorbance for a $15 \mu \mathrm{M} \mathrm{NO}_{3}{ }^{-}$solution $\left(2.5 \mathrm{~mL}\right.$ standard $+125 \mu \mathrm{L}$ Griess reagent $+250 \mu \mathrm{L} \mathrm{VCl}_{3}$-reagent); (C) and (D) corresponding minimum time required to reach the maximum absorbances for (A) and (B), respectively.

peratures $\left(70\right.$ and $\left.80^{\circ} \mathrm{C}\right), \mathrm{V}(\mathrm{III})$ reduces nitrate in $5 \mathrm{~min}-$ utes or less (Braman and Hendrix, 1989) and the produced nitrite reacts quickly with Griess reagent resulting in maximum signal in the first measurement $(5 \mathrm{~min}$ incubation) (Fig. 2A). However, the addition of reducing compounds has been proved to interfere in complex manners with the Griess reaction (Lebaron et al., 2002), resulting in a progressive reduction of molar absorption with time. In contrast, at $40^{\circ} \mathrm{C}$ the reaction was slow, resulting in reaction times exceeding 2 hours. At 50 and $60^{\circ} \mathrm{C}$, maximum responses were obtained after 40 and 15 min of incubation, respectively, and maintained constant for further $15 \mathrm{~min}$ of incubation (Fig. 2A). Considering that, the maximum molar absorptivity was obtained after $25 \mathrm{~min}$ of incubation at $60^{\circ} \mathrm{C}, 5 \%$ higher than the value obtained at $50^{\circ} \mathrm{C}$, the optimal conditions chosen for the method in the previous tests were confirmed.

\section{Optimization of the reagent volume}

Reagent volumes were adjusted to produce the minimal dilution of the sample and obtain the maximum molar absorbance. The maximum efficiency was obtained using $100 \mu \mathrm{L} 2 \% \mathrm{VCl}_{3}$-solution per $\mathrm{mL}$ of sample (Fig. 2B). With lower volumes, $\mathrm{VCl}_{3}$ concentration was probably too little to reduce the entire nitrate in the sample within $25 \mathrm{~min}$. In contrast, an excess of $\mathrm{VCl}_{3}$ favoured the further reduction of nitrite to nitric oxide, resulting in a decrease of the measured signal. On the other hand, Griess-reagent volumes over $25 \mu \mathrm{L}$ resulted in similar signal, being maxima with the addition of $50 \mu \mathrm{L}$ per $\mathrm{mL}$ of sample (Fig. 2B).

\section{Limit of detection, measuring range and stability}

The optimized conditions selected were tested in order to define the measuring range, detection limit and accuracy of the method (Fig. 3). When just $\mathrm{NO}_{3}{ }^{-}$was present, reaction was linear between $0-40 \mu \mathrm{M} \mathrm{NO}_{3}^{-}$ (Fig. 3A), similar to the one obtained by cadmium re- 

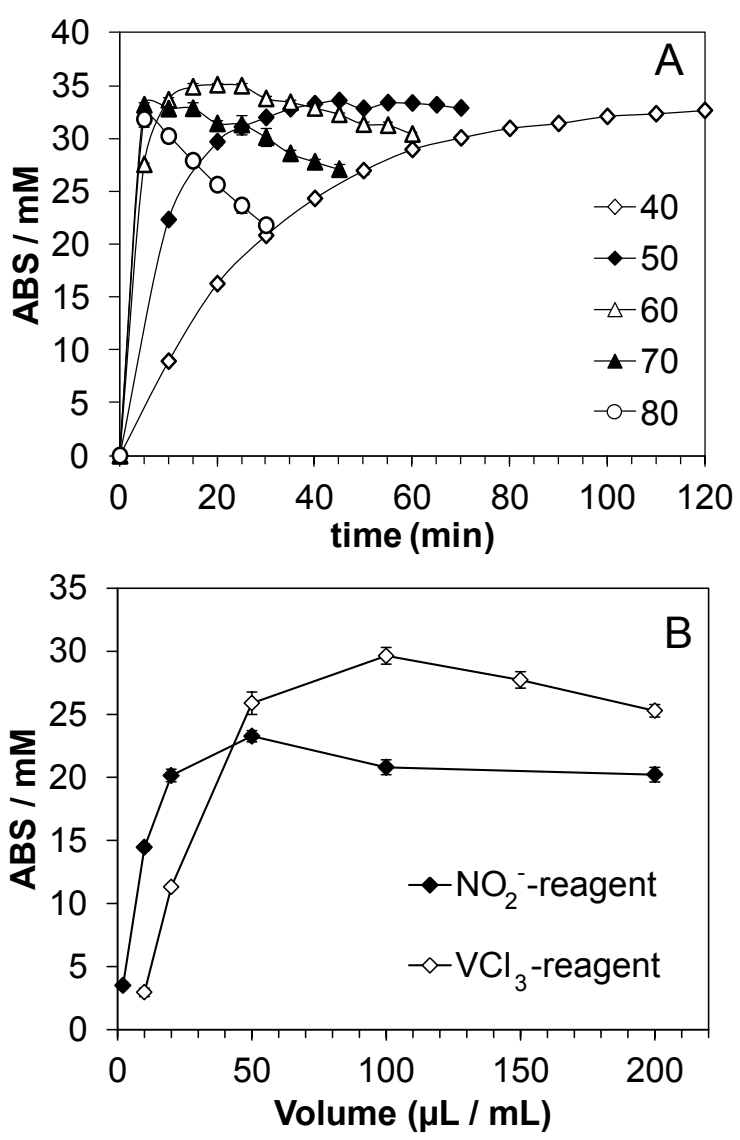

Figure 2. (A) Time evolution of the $\mathrm{NO}_{3}{ }^{-}$molar absorptivity at different temperatures following reaction $(1 \mathrm{~mL}$ standard + $50 \mu \mathrm{L}$ Griess-reagent $+100 \mu \mathrm{L} 2 \% \mathrm{VCl}_{3}$ in $\left.6 \mathrm{~N} \mathrm{HCl}\right)$ of $\mathrm{NO}_{3}^{-}$ calibration curves $(0-15 \mu \mathrm{M}$ range). Standards were measured every 5-10 minutes. (B) Effect of varied volumes of Griessreagent $(1 \mathrm{~mL}$ standard $+2,10,20,50,100$ or $200 \mu \mathrm{L}$ Griess reagent $+90 \mu \mathrm{L} \mathrm{VCl}_{3}$-reagent) and $\mathrm{VCl}_{3}$-reagent ( $1 \mathrm{~mL}$ standard $+50 \mu \mathrm{L}$ Griess reagent $+10,20,50,100,150$ or $200 \mu \mathrm{L}$

action columns (Wood et al., 1967), and within the range of nitrate concentrations commonly found in unpolluted aquatic environments.

The procedure showed a high precision. The standard deviation of the 6 standard replicates used for the calibration shown in Figure $3 \mathrm{~B}$ ranged from 0.01 to $0.11 \mu \mathrm{M}$, which mean a coefficient of variation between 0.2 to $11 \%$. The limit of detection (LOD) was calculated as 3 times the standard error of the intercept divided by the slope of the calibration as defined by Konieczka and Namiesnik (2009), resulting in a value as low as $0.04 \mu \mathrm{M} \mathrm{NO}_{3}{ }^{-}$.

As shown above, the reduction of $\mathrm{NO}_{3}{ }^{-}$and $\mathrm{NO}_{2}{ }^{-}$ with $\mathrm{V}$ (III) progresses rapidly at high temperatures, resulting in gradual decrease of the signal after 30-35 min at $60^{\circ} \mathrm{C}$ (Fib 2A). However, at slightly lower temperatures (e.g. $\left.40^{\circ} \mathrm{C}\right)$, the reaction slows down signifi- cantly, requiring several hours to reach maximum absorbances (Fig. 2A). Therefore, it is suggested that the reaction time should be controlled carefully to be 20-30 min at $60^{\circ} \mathrm{C}$ and then the samples to be cooled down to ambient temperature $\left(25^{\circ} \mathrm{C}\right)$. In this way, the signal remains stable for at least 1 hour, slowly decreasing with time thereafter (Fig. 3C). This procedure facilitates the analysis of a large number of samples simultaneously without the need to measure the absorbances of the samples immediately.

\section{Salt effect}

A slight decrease in the molar absorbance was observed with increasing salinities in the determination of $\mathrm{NO}_{2}{ }^{-}$using the common procedure of the Griess reaction $(\mathrm{ABS}=94.163+5.822 * \exp (-0.120+$ salinity $), \mathrm{r}$ $=0.958)$ (Fig. 4), in contrast to previous suggestions (Grasshoff et al., 1983). Norwitz \& Keliher (1985) also reported a salt effect but at much higher concentrations than the ones used here and for individual salts. The effect of salinity on the determination of $\mathrm{NO}_{2}^{-}$was the same when $\mathrm{VCl}_{3}$ was present in the reaction $(\mathrm{ABS}=$ $93.033+7.104 * \exp (-0.088+$ salinity $), \mathrm{r}=0.984)$. The salt effect remained stable in salinities between 20 and 50 , producing a molar absorbance about $94 \%$ of the value obtained in distilled water. A stronger effect was observed during $\mathrm{NO}_{3}{ }^{-}$determination in the presence of $\mathrm{VCl}_{3}$, with the molar absorptivity decreasing to $85 \%$ of the value obtained in distilled water at salinities between 30 and $50(\mathrm{ABS}=82.519+17.469 * \exp (-0.055$ + salinity), $r=0.998)$. Therefore, it is suggested that the calibration curves should be performed using standards at salinities similar to those found in the samples to be analyzed.

\section{Nitrite interference}

Environmental samples of marine and freshwater systems primarily contain $\mathrm{NO}_{3}{ }^{-}$, with $\mathrm{NO}_{2}{ }^{-}$being either absent or present at low concentrations. However, there are aquatic environments such as marine coastal areas and Oxygen Minimum Zones or fresh water hypolimnion where both $\mathrm{NO}_{3}{ }^{-}$and $\mathrm{NO}_{2}{ }^{-}$concentrations can increase and therefore both compounds should be measured accurately. The protocol described by Miranda. et al. (2001) described a fast and simple spectrophotometric protocol using $\mathrm{VCl}_{3}$ for $\mathrm{NO}_{3}{ }^{-}$reduction. However, they reported a high interference from $\mathrm{NO}_{2}^{-}$, with the error in the $\mathrm{NO}_{3}{ }^{-}$determination being proportional to the $\mathrm{NO}_{2}^{-}$concentration. As a result, the error in a sample with higher concentrations of $\mathrm{NO}_{2}{ }^{-}$than $\mathrm{NO}_{3}{ }^{-}$ could be superior than the actual $\mathrm{NO}_{3}{ }^{-}$concentration (Beda and Nedospasov, 2005).

After the complete reaction with $\mathrm{VCl}_{3}$, both the initial $\mathrm{NO}_{2}{ }^{-}$and $\mathrm{NO}_{2}{ }^{-}$from the reduction of $\mathrm{NO}_{3}{ }^{-}$will con- 

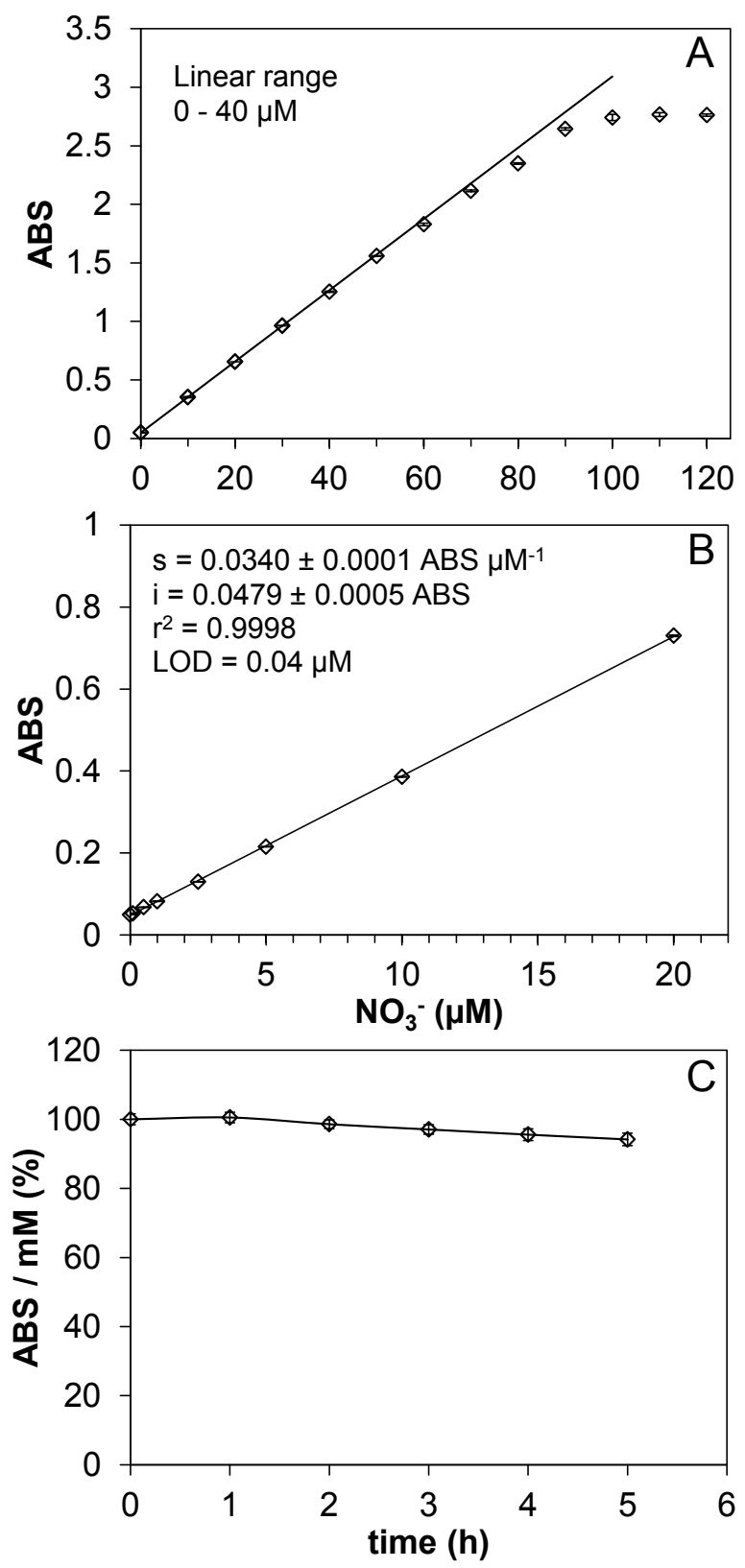

Figure 3. (A) Linear range, (B) low concentration calibration with the calculation of the limit of detection (LOD) and (C) decrease of the molar absorptivity over time at ambient temperature $\left(25^{\circ} \mathrm{C}\right)$ expressed as percentage of the initial. Reactions were carried out for 25 minutes at $60^{\circ} \mathrm{C}$ using $1 \mathrm{~mL} \mathrm{NO}_{3}^{-}$ standards $(\mathrm{n}=3-6)+50 \mu \mathrm{L}$ Griess-reagent $+100 \mu \mathrm{L} \mathrm{VCl}_{3-}$ reagent and absorbances measured using $1 \mathrm{~cm}$ cuvettes. Values are means $\pm \mathrm{SE}$.

tribute to the measured absorbance. However, the contribution of each compound to the total absorbance depends on a number of factors. The addition of the $\mathrm{VCl}_{3}$ reagent itself produces a slight dilution $(1: 1.1)$ of the

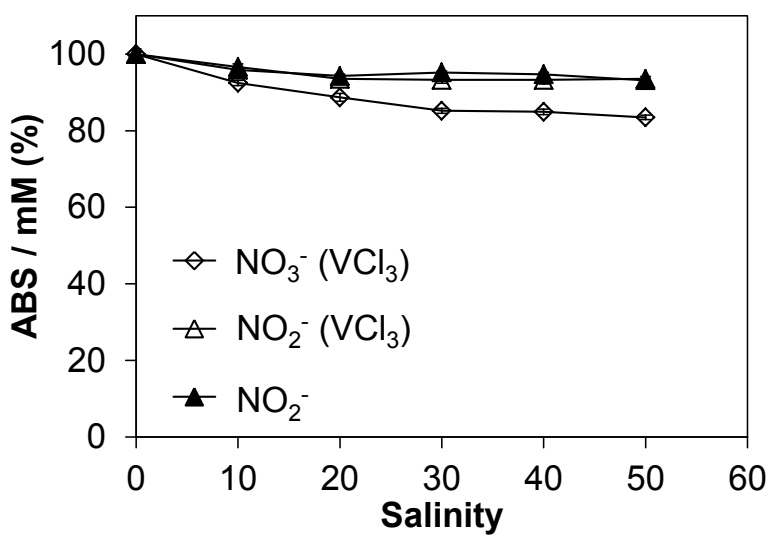

Figure 4. Effect of salinity on the molar absorptivity of $\mathrm{NO}_{2}{ }^{-}$in the normal Griess reaction and of $\mathrm{NO}_{3}{ }^{-}$and $\mathrm{NO}_{2}{ }^{-}$ after the reaction with $\mathrm{VCl}_{3}(1 \mathrm{~mL}+50 \mu \mathrm{L}$ Griess reagent $+100 \mu \mathrm{L} \mathrm{VCl}_{3}$-reagent) expressed as percentage of the value obtained in pure water (MilliQ). Values are means \pm SE.

usual Griess reagent/sample volume ratio, resulting in a decrease of the expected $\mathrm{NO}_{2}^{-}$molar absorptivity. In addition, the azo dye signal decreases with time likely caused by interference from the $\mathrm{VCl}_{3}$ reagent (Lebaron et al., 2002), which also reduces the $\mathrm{NO}_{2}{ }^{-}$molar absorptivity with time (Fig. 2). Thus, $\mathrm{NO}_{2}^{-}$molar absorptivity, as measured using solely $\mathrm{NO}_{2}^{-}$standards, decreases from a value of 0.042 to $0.036 \mathrm{ABS} \mu \mathrm{M}^{-1}$ after the addition of $\mathrm{VCl}_{3}$-reagent (Fig. 5A). This value was slightly lower than the theoretical decrease produced by dilution due to reagents addition (0.038 $\left.\mathrm{ABS} \mu \mathrm{M}^{-1}\right)$, emphasising the need to determine the effect of $\mathrm{VCl}_{3}$ reagent addition to the azo dye signal obtained in step 1 using a set of $\mathrm{NO}_{2}{ }^{-}$standards in parallel to those of $\mathrm{NO}_{3}^{-}$.

The efficiency of the $\mathrm{NO}_{3}{ }^{-}$reduction to $\mathrm{NO}_{2}^{-}$will also influence the measured signal; part of the $\mathrm{NO}_{3}{ }^{-}$ may not react, the $\mathrm{NO}_{2}^{-}$produced could further react with $\mathrm{VCl}_{3}$ or the $\mathrm{VCl}_{3}$ reagent could interfere with the azo dye production or signal, all resulting in efficiencies lower than $100 \%$. Indeed, the molar absorbance obtained for $\mathrm{NO}_{3}{ }^{-}$was slightly lower than that for $\mathrm{NO}_{2}{ }^{-}$, but the efficiency of the reaction was always higher than $90 \%$ (94\% in the example shown in Fig. 5A) during the tests of the method.

The method developed by Miranda. et al. (2001) achieved much lower molar absorptivities for $\mathrm{NO}_{3}{ }^{-}$that the ones observed in the present method due to 1) the larger volume of the reagents used by these authors, resulting in a 1:2 dilution of the sample and 2) a much lower conversion efficiency. The molar absorptivities obtained were $0.0089 \mathrm{ABS} \mu \mathrm{M}^{-1}$ which, after consider- 

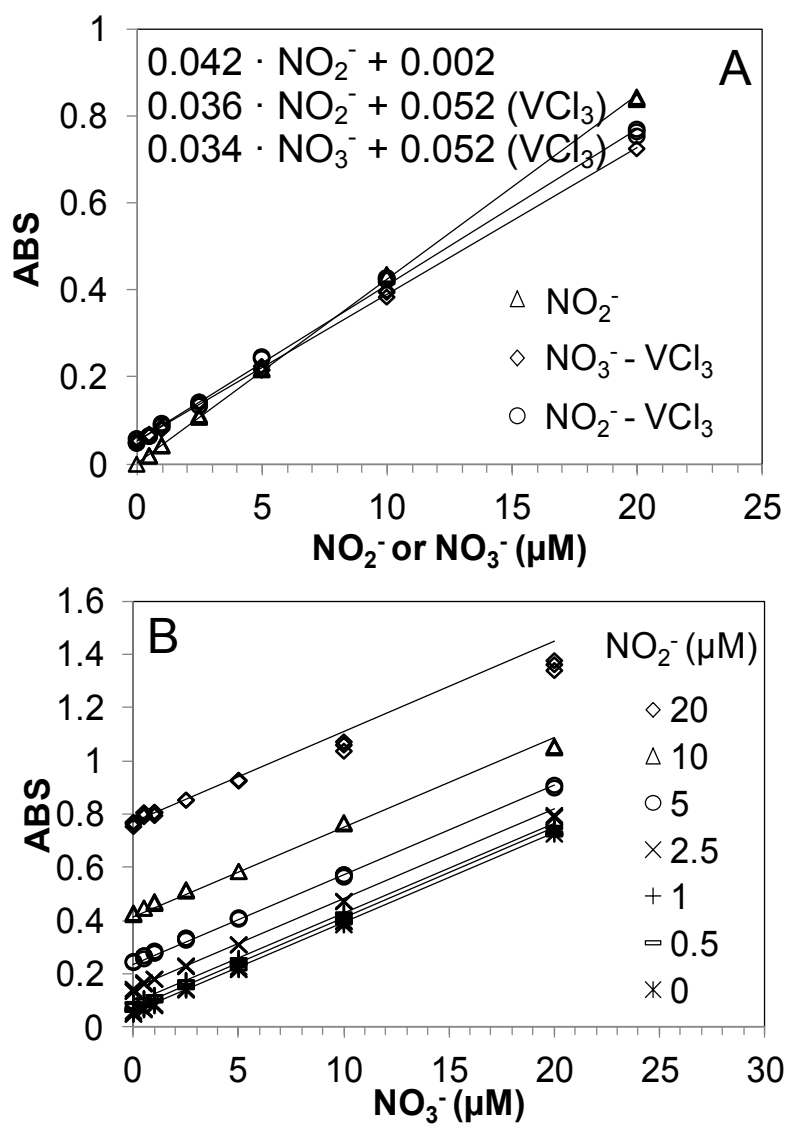

Figure 5. (A) Calibration curves obtained in the sequential measurement of $\mathrm{NO}_{2}{ }^{-}$and $\mathrm{NO}_{3}{ }^{-}$for $\mathrm{NO}_{2}{ }^{-}$after step 1 (standard + Griess-reagent) and separately for $\mathrm{NO}_{2}{ }^{-}$and $\mathrm{NO}_{3}{ }^{-}$after step 2 (sample + Griess-reagent $+\mathrm{VCl}_{3}$-reagent, 25 minutes reaction at $60^{\circ} \mathrm{C}$ ). Standard error was $<0.0003$ for the slopes and $<0.003$ for the intercepts. (B) $\mathrm{NO}_{3}{ }^{-}$calibrations curves $(0$ to $20 \mu \mathrm{M})$ measured in the presence of varied $\mathrm{NO}_{2}^{-}$concentrations $(0$ to $20 \mu \mathrm{M})$. Measured absorbance is represented as dots. Solid lines represent the calculated values using the calibration curves shown in (A) and equation 4 of the text.

ing the molar absorptivities obtained for $\mathrm{NO}_{2}^{-}$with the Griess reaction (around $0.038 \mathrm{ABS} \mu \mathrm{M}^{-1}$ ) and the dilution due to reagents as described their protocol, would signify a conversion efficiency of $\sim 40 \%$. As a result, the absorbance obtained per mol of $\mathrm{NO}_{2}^{-}$with the method of Miranda. et al. (2001) is more than 2 times higher than that for $\mathrm{NO}_{3}{ }^{-}$. In addition, the differential signal obtained for $\mathrm{NO}_{3}{ }^{-}$and $\mathrm{NO}_{2}{ }^{-}$was not taken into account, resulting in lower accuracy and a large $\mathrm{NO}_{2}^{-}$ interference.

In contrast, the procedure proposed here achieves a similar absorbance signal for both compounds, resulting in minimal $\mathrm{NO}_{2}^{-}$interference and high accuracy. In addition, the signal for each of the $\mathrm{NO}_{3}^{-}$and $\mathrm{NO}_{2}^{-}$is obtained separately during the calibration, and is constant during each analysis regardless of the $\mathrm{NO}_{2}{ }^{-} \mathrm{NO}_{3}{ }^{-}$ ratio present in the sample. This was confirmed by the low error $(=0.5 \mu \mathrm{M})$ measured in the determination of $\mathrm{NO}_{3}{ }^{-}$in standards with a range of $\mathrm{NO}_{2}^{-}$concentrations (Fig. 5B). Nitrate was, however, underestimated when the sum of $\mathrm{NO}_{2}^{-}$and $\mathrm{NO}_{3}^{-}\left(\mathrm{NO}_{\mathrm{X}}{ }^{-}\right)$concentrations exceeded $30 \mu \mathrm{M}$, which is higher than the upper limit for the measurement of $\mathrm{NO}_{2}^{-}$(Grasshoff et al., 1983). Therefore, for measurements of $\mathrm{NO}_{\mathrm{X}}^{-}$above $25 \mu \mathrm{M}$, especially with high $\mathrm{NO}_{2}{ }^{-}$concentrations $\left(>30 \% \mathrm{NO}_{\mathrm{X}}{ }^{-}\right.$), samples should be diluted in order to obtain an accurate $\mathrm{NO}_{3}{ }^{-}$measurement.

We have performed the complete procedure for large series of samples ( $>60$ samples) for the determination of both $\mathrm{NO}_{2}{ }^{-}$and $\mathrm{NO}_{3}{ }^{-}$in the same water sample $(=1 \mathrm{~mL})$ in less than one hour. The method can also be adapted to be performed in its entirety on the same microplate by first taking the absorbance reading for $\mathrm{NO}_{2}^{-}$ after step 1, heating on a microplate and for $\mathrm{NO}_{\mathrm{x}}{ }^{-}$after step 2. Thus, sample volumes $<300 \mu \mathrm{L}(250 \mu \mathrm{L}$ sample $+12.5 \mu \mathrm{L}$ Griess reagent $+25 \mu \mathrm{L} \mathrm{VCl}_{3}$-reagent) are utilised, making it especially suitable for analysis of sediment porewater samples.

\section{Comparison of cadmium column and vanadium methods}

Contribution of $\mathrm{NO}_{2}{ }^{-}$to $\mathrm{NO}_{\mathrm{x}}{ }^{-}$in the measured samples ranged from 0.2- 32.1\% (median 5.1\%). Samples were diluted appropriately (dilution factor range 1-12) to obtain $\mathrm{NO}_{\mathrm{x}}{ }^{-}$concentrations lower than $30 \mu \mathrm{M}$. Our diluted samples with a high $\mathrm{NO}_{2}^{-}$contribution showed $\mathrm{NO}_{\mathrm{x}}{ }^{-}$concentrations lower $20 \mu \mathrm{M}$. Comparison of the classical cadmium column reduction method and the protocol proposed here over a range of salinities (0-40) and type of samples (i.e. freshwater reservoir, acid mine drainage affected reservoir, estuarine, sediment freeze lysable) gave an excellent agreement between the two methods (Fig. 6). Paired t-test showed that the results from the two methods are homogenous $(\mathrm{t}=$ $0.736, p=0.472, n=17)$. Using the Cd column method as the reference methodology, the accuracy of the proposed method with $\mathrm{VCl}_{3}$ could be calculated as the difference between the measured samples (Konieczka and Namiesnik, 2009), resulting in an accuracy of $0.073 \pm$ $0.099 \mu \mathrm{M}$. These independent determinations show that the vanadium reduction method using spectrophotometry does not bias the results. Furthermore, 60 samples were analyzed for both $\mathrm{NO}_{2}{ }^{-}$and $\mathrm{NO}_{3}{ }^{-}$in less than $1 \mathrm{~h}$ by the vanadium method without the need of a specially trained technician and an expensive autoanalyser system by the automated cadmium column reduction method. 

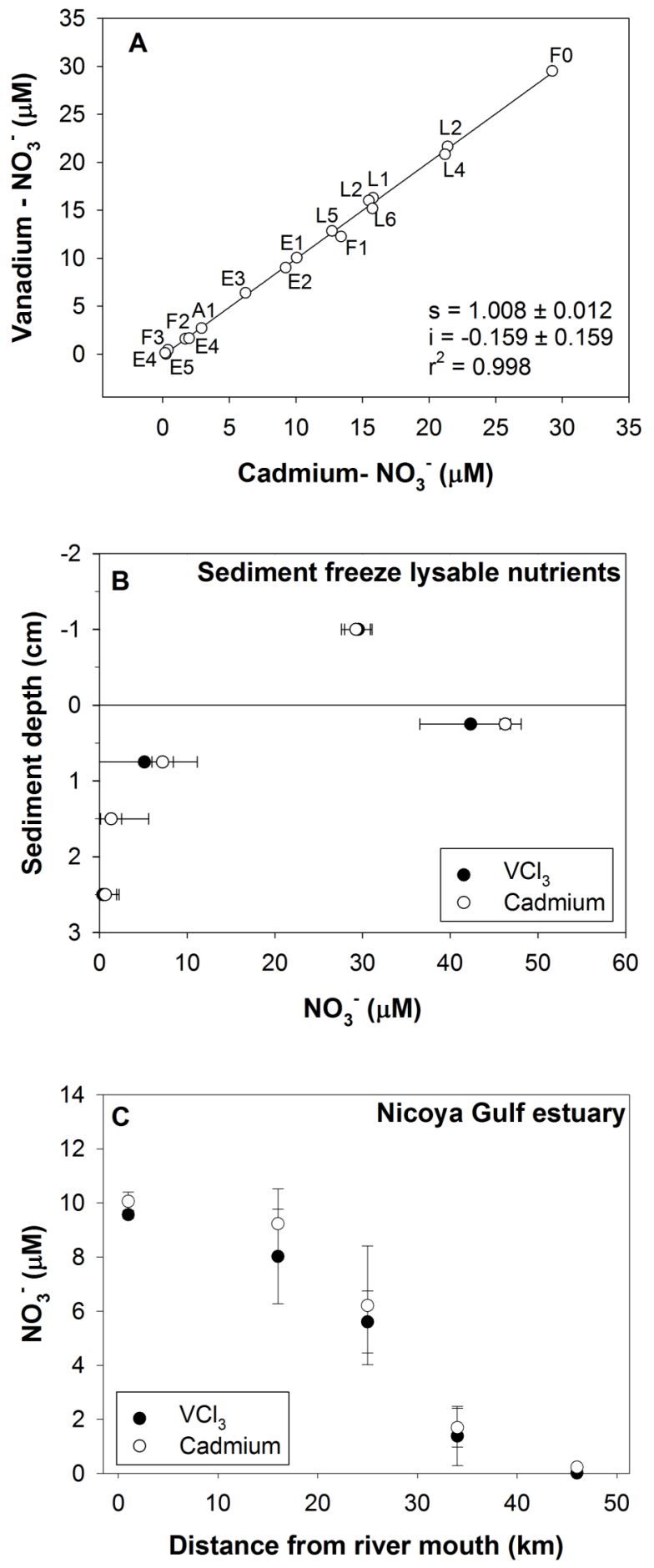

Figure 6. (A) Linear regression comparing the cadmium column and vanadium methods. L 1-6: Bornos water reservoir, A1: Sancho acid mine drainage impacted reservoir, E 1-5: Nicoya Gulf estuary, F 0-4: overlying water and sediment freeze lysable nutrient samples. Regression coefficients and standard error are shown $(\mathrm{n}=17)$. (B) Vertical profile of overlying water and sediment freeze lysable nitrate concentration in sediment from the inner Bay of Cadiz, Spain determined with the two methods. (C) Horizontal profile of nitrate concentrations measured with the two methods along the Nicoya Gulf estuary. Error bars on graphs (B) and (C) represent $95 \%$ confidence intervals.

\section{Conclusion}

We present a protocol for the sequential measurement of low $\mathrm{NO}_{2}^{-}$and $\mathrm{NO}_{3}^{-}$concentrations in both freshwater and marine samples based on an initial detection of $\mathrm{NO}_{2}^{-}$with Griess reagents followed by the reduction of the $\mathrm{NO}_{3}{ }^{-}$to $\mathrm{NO}_{2}^{-}$with $\mathrm{VCl}_{3}$ and subsequent detection with the excess Griess reagent present. The method has a detection limit $<0.05 \mu \mathrm{M}$ and a high accuracy and precision in the determination of both $\mathrm{NO}_{2}{ }^{-}$and $\mathrm{NO}_{3}{ }^{-}$for combined concentrations lower than $30 \mu \mathrm{M}$. The procedure does not require specialized equipment, expensive reagents or tedious procedures. The method allows the fast analysis of larges series of samples using low volumes, such as those of sediment porewater profiles.

\section{Acknowledgements}

We would like to thank Maria Morales and Jose Angel Gálvez for providing samples from the Bornos water reservoir and Juan Luis Jimenez Arias for the samples from the Sancho reservoir. Manolo Arjonilla, Instituto de Ciencias Marinas de Andalucia (CSIC), is acknowledged for excellent technical assistance with the Technicon autoanalyser. The research was funded by grants CTM 2009-10736 (Ministry of Education and Science, Spain), P11-RNM-7199(Andalusian Regional Government). S. Papaspyrou was funded by a JAE-Doc fellowship (Programa JAE, JAE-Doc109, Spanish National Research Council) and a Marie Curie ERG action (NITRICOS, 235005, European Union). E. GarcíaRobledo was funded by the Ramon Areces Foundation (Spain).

\section{References}

Aoki, T., Fukuda, S., Hosoi, Y. and Mukai, H., 1997. Rapid flow injection analysis method for successive determination of ammonia, nitrite, and nitrate in water by gas-phase chemiluminescence. Analytica Chimica Acta, 349(1-3): $11-16$.

Beda, N. and Nedospasov, A., 2005. A spectrophotometric assay for nitrate in an excess of nitrite. Nitric Oxide, 13 (2): 93-97.

Braman, R.S. and Hendrix, S.A., 1989. Nanogram nitrite and nitrate determination in environmental and biological materials by vanadium(III) reduction with chemiluminescence detection. Analytical Chemistry, 61(24): 27152718 . 
Christensen, S. and Tiedje, J.M., 1988. Sub-Parts-Per-Billion Nitrate Method: Use of an N2O-Producing Denitrifier to Convert NO3- or 15NO3- to N2O. Applied and environmental microbiology, 54(6): 1409-1413.

García-Robledo, E. et al., 2010. Freeze lysable inorganic nutrients in intertidal sediments: dependence on microphytobenthos abundance. Marine Ecology Progress Series 403: 155-163

Grasshoff, K., Ehrhardt, M. and Kremling, K., 1983. Methods of sea water analysis, 1. Verlag Chemie, New York.

Guevara, I. et al., 1998. Determination of nitrite/nitrate in human biological material by the simple Griess reaction. Clinica Chimica Acta, 274(2): 177-188.

Harris, S.J. and Mortimer, R.J.G., 2002. Determination of nitrate in small water samples (100?1) by the cadmiumcopper reduction method: a manual technique with application to the interstitial waters of marine sedimentsIntern. Journal of environmental and analytical Chemistry, 82(6): 369-376.

Jones, M.N., 1984. Nitrate reduction by shaking with cadmium. Alternative to cadmium columns. Water Research, 18(5): 643-646.

Konieczka, P. and Namiesnik, J., 2009. Quality assurance and quality control in the analytical chemical laboratory: a practical approach. Analytical chemistry series. CRC Press, Taylor \& Francis Group, Boca Raton, Florida.

Lashof, D.A. and Ahuja, D.R., 1990. Relative contributions of greenhouse gas emissions to global warming. Nature, 344 (6266): 529-531.

Lebaron, P. et al., 2002. Variations of bacterial-specific activity with cell size and nucleic acid content assessed by flow cytometry. Aquatic Microbial Ecology, 28(2): 131140.

Marzinzig, M. et al., 1997. Improved Methods to Measure End Products of Nitric Oxide in Biological Fluids: Nitrite, Nitrate, andS-Nitrosothiols. Nitric Oxide, 1(2): 177-189.

Megonigal, J.P., Hines, M.E. and Visscher, P.T., 2003. Anaerobic Metabolism: Linkages to Trace Gases and Aerobic Processes, Biogeochemistry. Treatise on Geochemistry. Elsevier Pergamon, pp. 317-424.

Mir, S.A., 2008. A rapid technique for determination of nitrate and nitric acid by acid reduction and diazotization at elevated temperature. Analytica Chimica Acta, 620(1-2): 183-189.
Miranda, K.M., Espey, M.G. and Wink, D.A., 2001. A Rapid, Simple Spectrophotometric Method for Simultaneous Detection of Nitrate and Nitrite. Nitric Oxide, 5(1): 62-71.

Norwitz, G. and Keliher, P.N., 1985. Study of Interferences in the Spectrophotometric Determination of Nitrite Using Composite Diazotisation - Coupling Reagents. Analyst, 110: 689-694.

Romero-Martínez, L. et al., 2013. Planktonic community metabolism in two stratified Mediterranean reservoirs with different trophic status. Aquatic Ecosystem Health \& Management, 16(2): 183-189.

Torres, E. et al., 2013. Metal cycling during sediment early diagenesis in a water reservoir affected by acid mine drainage. Science of The Total Environment, 461-462(0): 416-429.

Wood, E.D., Armstrong, F.A.J. and Richards, F.A., 1967. Determination of nitrate in sea water by cadmium-copper reduction to nitrite. Journal of the Marine Biological Association of the United Kingdom, 47(01): 23-31.

Zhang, J.-Z. and Fischer, C.J., 2006. A simplified resorcinol method for direct spectrophotometric determination of nitrate in seawater. Marine Chemistry, 99(1-4): 220-226. 